\title{
Microsatellite markers for Dictyochloropsis reticulata (Trebouxiophyceae), the symbiotic alga of the lichen Lobaria pulmonaria (L.)
}

\author{
Francesco Dal Grande • Ivo Widmer • \\ Andreas Beck $\cdot$ Christoph Scheidegger
}

Received: 19 March 2009/Accepted: 21 March 2009/Published online: 1 April 2009

(C) Springer Science+Business Media B.V. 2009

\begin{abstract}
We isolated and characterized eight microsatellite markers for Dictyochloropsis reticulata, the primary photosynthetic partner of the epiphytic lichen Lobaria pulmonaria. These are the first microsatellite loci reported for a lichen symbiotic alga. These polymorphic markers will be useful for investigating spatial genetic structure, biogeography and dispersal of this eukaryotic alga and will generally shed light on the coevolution of the green-algal lichen symbioses.
\end{abstract}

Keywords Coevolution - Lobaria pulmonaria . Photobiont · Population genetics · SSR

\section{Introduction}

The foliose tripartite lichen Lobaria pulmonaria has become an important model species for studies on the biological conservation of epiphytic lichens, because of its wide geographical distribution (Yoshimura 1998) and its value as a bioindicator of long ecological continuity (Gauslaa 1994). While L. pulmonaria is widespread and locally common in boreal North America (Brodo et al. 2001), it suffered a serious decline in many parts of Central Europe during the twentieth century (Wirth et al. 1996). Despite the amount of available biological and genetic

F. Dal Grande $(\bowtie) \cdot$ I. Widmer · C. Scheidegger

Biodiversity and Conservation Biology, WSL Swiss Federal

Research Institute, Zürcherstrasse 111, 8903 Birmensdorf,

Switzerland

e-mail: francesco.dalgrande@wsl.ch

A. Beck

Department of Lichenology and Bryology, Botanische

Staatssammlung München, 80638 Munich, Germany information for the fungal partner of this symbiosis (e.g. Walser et al. 2005; Werth et al. 2007), little is known about its primary photosymbiotic partner, namely the eukaryotic green alga Dictyochloropsis reticulata (Trebouxiophyceae; Geitler 1966), primarily because of a lack of informative genetic markers. In order to develop efficient strategies to conserve and enhance L. pulmonaria populations, more information is needed about patterns of genetic variation at different spatial scales for the algal part of the symbiosis. In this paper, we describe the isolation and characterization of eight informative microsatellite markers for D. reticulata, to provide adequate tools for corresponding population-level studies. To our knowledge, these are the first ones for a lichen symbiotic alga.

Following the method of Beck and Koop (2001), an axenic culture of $D$. reticulata was obtained and grown from a single algal cell isolated from a specimen of L. pulmonaria from Pamplona, Spain; voucher specimen 6577 (herbarium of the Swiss Federal Research Institute WSL, Birmensdorf), algal culture AB06.006A2 (algal culture collection of the Botanische Staatssammlung, Munich). Genomic DNA was extracted from $20 \mathrm{mg}$ of vegetative cells of $D$. reticulata using the DNeasy Plant Mini Kit (QIAGEN, Hilden, Germany) following the manufacturer's protocol. An enriched library was made by ecogenics GmbH (Zurich, Switzerland) from size selected genomic DNA ligated into SAULA/SAULB-linker (Armour et al. 1994) and enriched by magnetic bead selection with biotin-labelled $(\mathrm{GT})_{13},(\mathrm{CT})_{13},(\mathrm{TAC})_{10}$ and (AAC) 10 oligonucleotide repeats (Gautschi et al. 2000a, b). Of the 754 recombinant colonies screened, 127 gave a positive signal after hybridization. Plasmids from 104 positive clones were sequenced and primers were designed for 20 microsatellite inserts using PRIMER3 (Rozen and Skaletsky 2000). The 20 primer pairs were tested for PCR- 


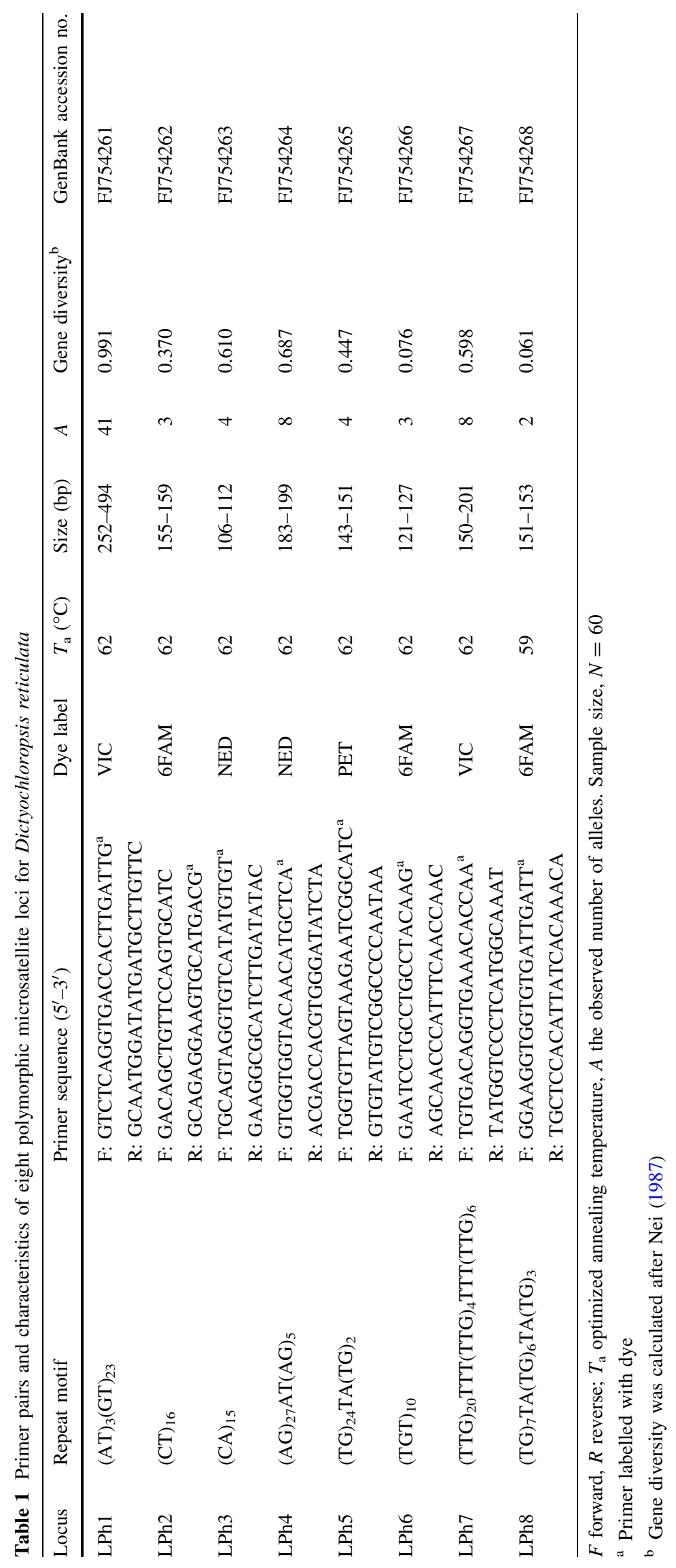


amplification with the genomic DNA obtained from the axenic culture of $D$. reticulata mentioned above. Six primer pairs failed to amplify, and fourteen were then used to screen for polymorphism with a sample of 60 specimens of L. pulmonaria (North Carolina, USA). Total genomic DNA was extracted from the lichen thalli using the DNeasy 96 Plant Kit (QIAGEN, Hilden, Germany) according to the manufacturer's protocol. PCR reactions for the alga-specific microsatellites were performed on an Applied Biosystems Veriti thermal cycler (Applied Biosystems, Foster City, CA) in a $10 \mu \mathrm{l}$ reaction mixture containing 1$10 \mathrm{ng}$ of template DNA, $0.2 \mu \mathrm{M}$ of each primer and $1 \times$ Multiplex PCR Kit (QIAGEN, Hilden, Germany). PCR conditions were as follows: $15 \mathrm{~min}$ at $95^{\circ} \mathrm{C}, 25$ cycles of $30 \mathrm{~s}$ at $94^{\circ} \mathrm{C}, 90 \mathrm{~s}$ at $62^{\circ} \mathrm{C}$ (or $59^{\circ} \mathrm{C}$ for $\mathrm{LPh} 8$ ), $60 \mathrm{~s}$ at $72^{\circ} \mathrm{C}$ and a final elongation for $30 \mathrm{~min}$ at $60^{\circ} \mathrm{C}$. Genotyping was performed on an ABI 3730 Genetic Analyser (Applied Biosystems, Foster City, CA) and electropherograms were analyzed with GENEMAPPER v3.7 using LIZ500 size standard (Applied Biosystems, Foster City, CA).

Eight of the fourteen tested loci were polymorphic (Table 1). In all individuals, a single allele was recovered per locus. This indicates that $D$. reticulata is haploid. Gene diversity per locus (Nei 1987) ranged from 0.061 to 0.991 , and the number of alleles per locus varied from 2 to 41 alleles, resulting in 52 unique multilocus genotypes. The primer sequences and other characteristics for the microsatellite loci are given in Table 1. Linkage disequilibrium in pairwise combinations of the loci was tested using GENEPOP 4.0 ON THE WEB (Raymond and Rousset 1995). After Bonferroni correction, no significant linkage disequilibrium was detected.

These eight microsatellite loci are currently used for studying the spatial population structure, phylogeography and dispersal of $D$. reticulata. Of particular interest is their application to investigate whether different lichen-forming fungi share the same photobiont. When used in combination with the fungus-specific microsatellites for $L$. pulmonaria (Walser et al. 2003; Widmer et al. in prep.), these markers are a promising tool for studying coevolution of the green-algal lichen symbiosis.

Acknowledgments We thank C Cornejo for laboratory assistance, $\mathrm{R}$ Holderegger for valuable comments on the manuscript and $\mathrm{T}$ Terzani for his never-ending support. We also thank the Genetic Diversity Center at ETH Zürich, Switzerland (CCED-GDC) for technical assistance. We acknowledge financial support from the
Swiss National Science Foundation (projects 31003A-105830 and 31003A-127346 to Christoph Scheidegger).

\section{References}

Armour JA, Neumann R, Gobert S, Jeffreys AJ (1994) Isolation of human simple repeat loci by hybridization selection. Hum Mol Genet 3:599-605. doi:10.1093/hmg/3.4.599

Beck A, Koop H-U (2001) Analysis of the photobiont population in lichens using a single-cell manipulator. Symbiosis 31:57-67

Brodo IM, Duran Sharnoff S, Sharnoff S (2001) Lichens of North America. Yale University Press, London

Gauslaa Y (1994) Lobaria pulmonaria, an indicator of species-rich forests of long ecological continuity. Blyttia 52:119-128

Gautschi B, Tenzer I, Müller JP, Schmid B (2000a) Isolation and characterization of microsatellite loci in the bearded vulture (Gypaetus barbatus) and cross-amplification in three Old World vulture species. Mol Ecol 9:2193-2195. doi:10.1046/j.1365294X.2000.105321.X

Gautschi B, Widmer A, Koella J (2000b) Isolation and characterization of microsatellite loci in the Dice Snakje (Natrix tessellata). Mol Ecol 3:233-235

Geitler L (1966) Die Chlorococcalen Dictyochloris und Dictyochloropsis. Österreich Bot Zeitschr 113:155-164

Nei M (1987) Molecular evolutionary genetics. Columbia University Press, New York

Raymond M, Rousset F (1995) GENEPOP (version 1.2): population genetics software for exact tests and ecumenicism. J Hered $86: 248-249$

Rozen S, Skaletsky H (2000) PRIMER3 on the WWW for general users and for biologist programmers. In: Krawetz S, Misener S (eds) Bioinformatics methods and protocols in the series methods in molecular biology. Humana Press, Totowa, pp 365-386

Walser JC, Sperisen C, Soliva M, Scheidegger C (2003) Fungusspecific microsatellite primers of lichens: application for the assessment of genetic variation on different spatial scales in Lobaria pulmonaria. Fungal Genet Biol 40(1):72-82. doi: 10.1016/S1087-1845(03)00080-X

Walser JC, Holderegger R, Gugerli F, Hoebee SE, Scheidegger C (2005) Microsatellites reveal regional population differentiation and isolation in Lobaria pulmonaria, an epiphytic lichen. Mol Ecol 14(2):457-467. doi:10.1111/j.1365-294x.2004.02423.x

Werth S, Gugerli F, Holderegger R, Wagner HH, Csencsics D, Scheidegger C (2007) Landscape-level gene flow in Lobaria pulmonaria, an epiphytic lichen. Mol Ecol 16:2807-2815. doi: 10.1111/j.1365-294X.2007.03344.x

Wirth V, Scholler H, Scholz P et al (1996) Rote Liste der Flechten (Lichenes) der Bundesrepublik Deutschland. Schriftenr Vegetationsk 28:307-368

Yoshimura I (1998) Lung lichens and their vegetation in Japan and other regions. In: Kondratyuk SY, Coppins BJ (eds) Lobarion Lichens as indicators of the primeval forests of the Eastern Carpathians. Ukrainian Phytosociological Centre, Kiev, pp 53-63 